\title{
Neuropsychiatric Complications of COVID-19: What Is to Be Expected
}

\author{
Maral Seyed Ahadi ${ }^{1}$, Nasim Rezaeimanesh (iD) ${ }^{1}$ and Abdorreza Naser Moghadasi (iD ${ }^{1, *}$ \\ ${ }^{1}$ Multiple Sclerosis Research Center, Neuroscience institute, Tehran University of Medical Sciences, Tehran, Iran \\ "Corresponding author: Multiple Sclerosis Research Center, Neuroscience institute, Tehran University of Medical Sciences, Tehran, Iran. Email: \\ abdorrezamoghadasi@gmail.com
}

Received 2020 July 04; Revised 2020 November 16; Accepted 2020 November 22.

Keywords: Mental Health, COVID-19, Neuropsychiatric Complications

\section{Introduction}

Coronavirus disease 2019 (COVID-19), identified on December 31st, 2019, has become a problem for governments and health care providers worldwide. While biomedical scientists continue their efforts to develop vaccines and medications, the social and neuropsychological aspects of COVID-19 and its impacts on the cognitive process should not be ignored $(1,2)$.

\section{Neuropsychiatric Complications of COVID-19}

There are different aspects of the aforementioned issues as follows:

1- COVID-19 has been associated with a number of neurologic complications like anosmia, which is the most common and least morbid one. Other reported complications were encephalitis, viral meningitis, myositis, post-infectious acute disseminated encephalomyelitis, Guillain-Barre syndrome, and post-infectious brainstem encephalitis (3). The cognitive complications of neurologic manifestations of COVID-19 are yet to be evaluated. Accordingly, these neurologic complications can affect cognitive processing in infected patients. Previous studies conducted on other causes of sporadic viral encephalitis, including other strains of human coronavirus, have shown different psychiatric and cognitive deficits, ranging from depression to acute psychosis (4-7). In a study by Pewter et al. (6), it was shown that the most consistent damaged domain of cognition in viral encephalitis rather than Herpes Simplex virus was related to executive function, with planning and monitoring behavior and verbal response suppression being the most commonly damaged ones. They suggested that these specific elements of cognition may be more susceptible to impairment in some slighter forms of encephalitis (6). Furthermore, there are numerous reports on encephalopathy in patients with COVID-19, either with infection initiation or after admission to the hospital (8).

2- Premorbid conditions such as Alzheimer's disease or other cognitive disorders may worsen this state, as the cognitive reserve is diminished, and a superimposed infection can cause delirium. The demented COVID-19 patients staying in nursing homes are mostly at the risk of developing delirium due to social distancing policies leading to the ban of visitors, and even worse if admitted to intensive care units, leading to the increased stress and behavioral problems (9). Furthermore, there is evidence that delirium might contribute to permanent neuronal damage and dementia by itself (10), which may have upcoming complications that yet to be encountered.

3- On the other hand, there are psychological events related to a pandemic, as a pandemic can precipitate new psychiatric symptoms in the normal population such as anxiety, depression, obsession, and paranoia, with a greater impact on the patients with psychiatric disorders. Brooks et al. (11) assessed the psychological impact of quarantine in 2003 due to severe acute respiratory syndrome (SARS) and in 2014 due to the Ebola outbreak in a systematic review, with most of the reviewed studies reporting negative psychological effects, including anger, confusion, and post-traumatic stress symptoms. A constant stream of information on disease distribution and mortality could lead to anxiety. Also, emphasis on personal hygiene and environmental measures to decrease the transmission may increase obsession in the patients with obsessivecompulsive disorders, and in some instances, may be accompanied by paranoia. Restrictive practices such as social distancing and quarantine, in the countries that were applied, could lead to depression and decreased access to clinic-based medical care and cognitive behavioral therapy, which in turn could aggravate the issue. Mortalities could additionally worsen the situation as even funerals 
and ceremonies are forbidden in the involved countries (12), and also, the grief period for families and relatives can be influenced by social distancing, and proper grieving is not possible, extending the grief period, occasionally leading to the prolonged grief disorder(PGD). There are studies demonstrating lower attention and global cognitive performance in individuals with PGD and a stronger cognitive decline over time (13-15); therefore, future complications should be anticipated.

4- Another aspect that is not still fully encountered is that after the acute phase and recovering from the illness, COVID-19 survivors may be subjected to stigmatization originating from public fear in transmission and may be considered the subjects of long-lasting social distancing. Patient caregivers and healthcare workers could also be targets of stigmatization. In the previous SARS epidemic, a public study conducted in Hong Kong stated that $16.2 \%$ of those who were studied said that, even after 18 months from complete treatment, SARS survivors might still transmit the virus to other people; and 16.6\% had the tendency to avoid from having communication with SARS survivors (16). This illness-related stigmatization may result in anxiety and depression but can cause an inability to engage in normal social life and career (17).

\section{Treatment}

The importance of case detection, resource allocation, and treatment strategies of the rapidly extending pandemic has extensively engaged public health authorities, with much-lowered consideration on psychological issues. However, along with the increasing psychological problem during the COVID-19 outbreak, mental health support starts to find its way into the spotlights. There are some strategies applicable to be accounted for the psychological burden and to reduce that. The government and health authorities should provide public with accurate health information and update about the epidemic to tackle the effect of misinformation circulated throughout social media and reducing anxiety. A recent study by Wang et al. (18) showed that regular updates and information regarding the satisfaction of the health data received has been found to be associated with lesser mental distress and lower levels of stress, anxiety, and depression. Targeted education for stress management, relaxation techniques, and hygiene and also prevention modalities for the general population and special conditions should be available for different ages. Online psychological counseling has been allocated in the countries dealing with the pandemic, like China, as the first country facing the psychosocial challenges of the pandemic (19). Healthcare providers should facilitate the availability of telemedicine to identify new cases and monitor the treatment of the patients. Psychological interventions such as cognitive behavior therapy (CBT) and mindfulness-based cognitive behavior therapy (MBCT), should be tailored in terms of the social distancing strategies allocated by the health care policymakers. Identification and treatment of the patients with complicated grief should be targeted by specialized therapists, implementing complicated grief treatment that was occasionally combined with appropriate medications (20). Finally, a systematic investigation of how COVID-19 can adversely affect the patients' psychological issue is mandatory; Therefore, appropriate interventions may be applied for individual, family, and social levels.

\section{Conclusions}

COVID-19 has become a health issue for governments and health care providers worldwide. Although biomedical scientists continue their efforts to develop vaccines and medications for this disease, the social and neuropsychological aspects of COVID-19 and its impacts on cognitive processing should not be overlooked.

\section{Footnotes}

Authors' Contribution: Study concept and design: ANM. Searching and drafting the manuscript: MSA, NR, and ANM. critical revision of the manuscript for important intellectual content: ANM.

Conflict of Interests: The authors declare no conflict of interest.

Funding/Support: None.

\section{References}

1. Aghili SM, Arbabi M. The COVID-19 Pandemic and the Health Care Providers; What Does It Mean Psychologically? Adv J Emerg Med. 2020;4(2s):e63.

2. Pothiawala S. Psychological Impact of the COVID-19 on Health Care Workers in the Emergency Department. Adv J Emerg Med. 2020;4(2s):e58.

3. Nath A, Berger JR. Neurological manifestations of coronavirus infections. Clinical Neurovirology. 2020.p. 439-42. doi: 10.1201/978131511391334.

4. Okusaga O, Yolken RH, Langenberg P, Lapidus M, Arling TA, Dickerson FB, et al. Association of seropositivity for influenza and coronaviruses with history of mood disorders and suicide attempts. J Affect Disord. 2011;130(1-2):220-5. doi: 10.1016/j.jad.2010.09.029. [PubMed: 21030090]. [PubMed Central: PMC3043161].

5. Severance EG, Dickerson FB, Viscidi RP, Bossis I, Stallings CR, Origoni $\mathrm{AE}$, et al. Coronavirus immunoreactivity in individuals with a recent onset of psychotic symptoms. Schizophr Bull. 2011;37(1):101-7. doi: 10.1093/schbul/sbp052. [PubMed: 19491313]. [PubMed Central PMC3004184]. 
6. Pewter SM, Williams WH, Haslam C, Kay JM. Neuropsychological and psychiatric profiles in acute encephalitis in adults. Neuropsychol Rehabil. 2007;17(4-5):478-505. doi: 10.1080/09602010701202238. [PubMed: 17676531].

7. Lee AM, Wong JG, McAlonan GM, Cheung V, Cheung C, Sham PC, et al. Stress and psychological distress among SARS survivors 1 year after the outbreak. Can J Psychiatry. 2007;52(4):233-40. doi: 10.1177/070674370705200405. [PubMed: 17500304].

8. Filatov A, Sharma P, Hindi F, Espinosa PS. Neurological Complications of Coronavirus Disease (COVID-19): Encephalopathy. Cureus. 2020;12(3). e7352. doi: 10.7759/cureus.7352. [PubMed: 32328364]. [PubMed Central: PMC7170017].

9. Wang H, Li T, Barbarino P, Gauthier S, Brodaty H, Molinuevo JL, et al. Dementia care during COVID-19. Lancet. 2020;395(10231):1190-1. doi: 10.1016/s0140-6736(20)30755-8.

10. Fong TG, Davis D, Growdon ME, Albuquerque A, Inouye SK. The interface between delirium and dementia in elderly adults. Lancet Neurol.2015;14(8):823-32. doi:10.1016/S1474-4422(15)00101-5. [PubMed: 26139023]. [PubMed Central: PMC4535349].

11. Brooks SK, Webster RK, Smith LE, Woodland L, Wessely S, Greenberg $\mathrm{N}$, et al. The psychological impact of quarantine and how to reduce it: rapid review of the evidence. Lancet. 2020;395(10227):912-20. doi: 10.1016/s0140-6736(20)30460-8.

12. Lazzerini M, Putoto G. COVID-19 in Italy: momentous decisions and many uncertainties. Lancet Glob Health. 2020;8(5):e641-2. doi: 10.1016/S2214-109X(20)30110-8. [PubMed: 32199072]. [PubMed Central: PMC7104294].

13. Perez HCS, Ikram MA, Direk N, Tiemeier H. Prolonged Grief and Cognitive Decline: A Prospective Population-Based Study in Middle-Aged and Older Persons. Am J Geriatr Psychiatry. 2018;26(4):451-60. doi: 10.1016/j.jagp.2017.12.003. [PubMed: 29329723].
14. Hall CA, Reynolds C3, Butters M, Zisook S, Simon N, Corey-Bloom $J$, et al. Cognitive functioning in complicated grief. $J$ Psychiatr Res. 2014;58:20-5. doi: 10.1016/j.jpsychires.2014.07.002. [PubMed: 25088285]. [PubMed Central: PMC4163517].

15. Saavedra Perez HC, Ikram MA, Direk N, Prigerson HG, Freak-Poli R, Verhaaren BF, et al. Cognition, structural brain changes and complicated grief. A population-based study. Psychol Med. 2015;45(7):1389-99. doi: 10.1017/S0033291714002499. [PubMed: 25363662].

16. Lau JT, Yang X, Wong E, Tsui H. Prevalence and factors associated with social avoidance of recovered SARS patients in the Hong Kong general population. Health Educ Res. 2006;21(5):66273. doi: 10.1093/her/cyl064. [PubMed: 16880214]. [PubMed Central: PMC7108544].

17. Link BG, Phelan JC. Stigma and its public health implications. Lancet. 2006;367(9509):528-9. doi: 10.1016/S0140-6736(06)68184-1. [PubMed: 16473129].

18. Wang C, Pan R, Wan X, Tan Y, Xu L, Ho CS, et al. Immediate Psychological Responses and Associated Factors during the Initial Stage of the 2019 Coronavirus Disease (COVID-19) Epidemic among the General Population in China. Int J Environ Res Public Health. 2020;17(5). doi: 10.3390/ijerph17051729. [PubMed: 32155789]. [PubMed Central: PMC7084952].

19. Liu S, Yang L, Zhang C, Xiang YT, Liu Z, Hu S, et al. Online mental health services in China during the COVID-19 outbreak. Lancet Psychiatr. 2020;7(4):e17-8. doi: 10.1016/S2215-0366(20)30077-8. [PubMed: 32085841]. [PubMed Central: PMC7129099].

20. Shear MK, Reynolds C3, Simon NM, Zisook S, Wang Y, Mauro C, et al. Optimizing Treatment of Complicated Grief: A Randomized Clinical Trial. JAMA Psychiatry. 2016;73(7):685-94. doi: 10.1001/jamapsychiatry.2016.0892. [PubMed: 27276373]. [PubMed Central: PMC5735848]. 